\title{
AN EXPLORATORY STUDY EVALUATING EXPERIENCED STIGMA AMONG DOCTORS IN A DEDICATED COVID-19 HOSPITAL OF NORTH INDIA
}

\author{
JASMIN GARG, ADITI SINGLA, ROHIT GARG* \\ Department of Psychiatry, Government Medical College, Patiala, Punjab, India. Email: drrohitgarg@hotmail.com
}

Received: 04 December 2021, Revised and Accepted: 15 January 2022

ABSTRACT

Objective: Doctors may experience stigma and discrimination from community, friends and even family due to their association with COVID-19 patients. The present study was planned to assess actual stigma experienced by doctors because of working in COVID-19 wards.

Methods: A cross-sectional study was conducted in the Department of Psychiatry of a dedicated COVID-19 Hospital of North India. A Google Survey Form which measured Experienced Stigma was circulated through WhatsApp groups in October-November 2020 among all the doctors working in COVID-19 ward. Data collected was analyzed statistically.

Results: Around 250 doctors participated in the study and $70 \%$ of them experienced stigma in one or more ways. Approximately, $60 \%$ doctors had stopped socializing because of people's reactions, they felt that people were afraid of them and that people avoided touching them because they were treating patients with COVID-19. 110 (44\%) respondents were denied social exchanges/friendships, 88 (35.2\%) felt neglected by family or friends, and $71(28.4 \%)$ lost friendships because they worked with patients with COVID-19. Stigma was experienced significantly higher in younger age $\left(\mathrm{p}=0.012^{*}\right)$, resident doctors $\left(\mathrm{p}=0.001^{* *}\right)$ and those with longer working hours $\left(\mathrm{p}=0.01^{*}\right)$.

Conclusion: Doctors experience stigma from friends, family and general public due to their contact with COVID-19 patients. Experienced stigma is higher in young age and resident doctors.

Keywords: COVID-19, Doctors, Experienced stigma.

(c) 2022 The Authors. Published by Innovare Academic Sciences Pvt Ltd. This is an open access article under the CC BY license (http://creativecommons.org/ licenses/by/4.0/) DOI: http://dx.doi.org/10.22159/ajpcr.2022v15i2.43889. Journal homepage: https://innovareacademics.in/journals/index.php/ajpcr

\section{INTRODUCTION}

COVID-19 was recognized as a pandemic in March 2020 by the WHO as it rose exponentially in numbers throughout the world [1]. As of $5^{\text {th }}$ August 2021, there were 20,01,74,883 confirmed cases and $42,55,892$ deaths due to COVID-19 globally and the respective numbers in India were 3,18,12,114 and 4,26,290 [2].

Stigma is often associated with infectious illnesses [3], and there is emerging data about stigma associated with COVID-19 [4,5]. Stigma can be public stigma (public attitudes toward a stigmatized group), perceived stigma (stigma perceived by the stigmatized group to be present against them in the community), or experienced stigma (actual instances of discrimination and stigma faced by the stigmatized group) [6].

The community has extreme fear and anxiety towards COVID-19 perpetuated by mass media and other means [7]. Health care workers (HCWs) are thus predisposed to experiencing stigma because they treat patients with COVID-19 [8-10]. HCWs are already overburdened and they experience stress, anxiety and depressive symptoms, plus they put themselves and their families at risk due to COVID-19 [11-13]. This could be a double jeopardy for HCWs. The incidents of violence against doctors are also increasing $[4,8,10,14]$.

Some previous studies have assessed perceived stigma [15-17], while there is almost negligible literature on experienced stigma among doctors working with COVID-19 patients [18,19]. The current study aimed to assess actual stigma experienced by doctors in the area of their close relationships. The data for the current study was derived from larger research on stigma and stress among doctors working in COVID-19 hospital [20].

\section{METHODS}

This study was conducted by the Department of Psychiatry of a tertiary care center of North India. The hospital had Category-I [21] COVID inpatient facility for 600 patients. All the doctors working in this hospital, irrespective of their specialization were trained and engaged in the care of COVID-19 patients in morning, evening and night shifts. In between the isolation ward duties, they continued to work in their respective departments for routine non-COVID duties without quarantine leaves. The designation of the participant doctors were (Junior Residents [JRs] or post-graduate students), Senior Residents (SRs) and Faculty. Those who themselves or those whose family members had suffered from COVID-19, were excluded from the study. The doctors were surveyed about the experienced stigma through a Google survey form, the methodology of which has been explained in the parent study [20]. It was circulated once a week in their respective WhatsApp groups in October and November 2020.

Institutional Ethics Committee clearance was obtained before circulation of the survey form. The Indian Council of Medical Research guidelines for biomedical research in human subjects were followed as applicable [22]. The survey form also incorporated consent and confidentiality statements.

Following assessments were taken in the present study:

\section{Socio-demographic data}

Participants' age, gender, marital status, designation and their working hours per week in COVID-19 facility were noted.

Questionnaire for measuring experienced stigma

This was adapted from the "Health Facility and Provider Stigma Measurement Questionnaire" which is an index to measure fear 
and stigma among health care professionals working with HIV patients [23]. It is a 31-item questionnaire in which 25 questions are regarding HIV knowledge, fear and value driven stigma. Rest of the six questions measure experienced stigma and thus only these were taken for the present study. These questions measure actual instances of discrimination experienced by HCWs from other people (especially from their friends and family) due to their working closely with HIV positive patients. These questions were modified by replacing the term "HIV" with "COVID-19". There are four set of responses namely, "strongly disagree, disagree, agree and strongly agree" to each question with a score of 1, 2, 3 and 4, respectively. All these statements are positively worded, indicating higher stigma for higher score.

Statistical analysis was carried out using SPSS (version 25; Chicago, IL). The level of statistical significance was set at a $\mathrm{p} \leq 0.05$. Student $\mathrm{t}$-test and Pearson correlation test were used for analysis of data. Survey forms were closely scrutinized for ruling out duplication, by matching the socio-demographic data. No duplication was found and thus all the entries were included in the study.

\section{RESULTS}

Out of the 753 doctors working in this hospital, 250 (33.20\%) participated. Mean age of the participants was $35.40 \pm 10.7$ years and mean duration of time spent in the COVID-19 duties was $29.73 \pm 16.3 \mathrm{~h}$ per week. There were 107 males (42.7\%) and 143 females (57.2\%). 133 (53.2\%) respondents were married and rest 117 (46.8\%) were unmarried. There were 133 (53.2\%) JRs, 31 (12.4\%) SRs, and 86 (34.4\%) faculty respondents. The total mean experienced stigma score was $14.45 \pm 4.44$.

Experienced stigma and its association with socio-demographic variables

There was no significant difference in stigma score between males and females $(\mathrm{p}=0.953)$ or between married and unmarried doctors

Table 1: Experienced Stigma and its association with socio-demographic variables

\begin{tabular}{llll}
\hline Variable (N) & Mean \pm SD & t-test & p-value \\
\hline Gender & & & \\
$\quad$ Male (107) & $14.47 \pm 4.72$ & 0.059 & 0.953 \\
$\quad$ Female (143) & $14.43 \pm 4.24$ & & \\
Designation & & & \\
$\quad$ Faculty (86) & $13.24 \pm 4.03$ & 7.675 & $0.001^{* *}$ \\
$\quad$ SRs (31) & $16.68 \pm 4.93$ & & \\
JRs (133) & $14.71 \pm 4.37$ & & \\
Marital status & & & \\
$\quad$ Married (133) & $14.18 \pm 4.24$ & 1.015 & \\
$\quad$ Unmarried (117) & $14.75 \pm 4.66$ & & \\
\hline *p $<0.05,{ }^{* *} \mathrm{p}<0.01$, SRs: Senior Residents, JRs: Junior Residents &
\end{tabular}

Table 2: Responses on each item of experienced stigma scale

\begin{tabular}{|c|c|c|c|}
\hline \multicolumn{2}{|c|}{ Experienced stigma } & \multicolumn{2}{|l|}{ Response N (\%) } \\
\hline & & \multirow{2}{*}{$\begin{array}{l}\text { Disagree/strongly disagree } \\
162(64.8)\end{array}$} & \multirow{2}{*}{$\begin{array}{l}\text { Agree/strongly agree } \\
88(35.2)\end{array}$} \\
\hline 1. & $\begin{array}{l}\text { I have been neglected by family and friends because I care for COVID-19 positive } \\
\text { patients. }\end{array}$ & & \\
\hline 2. & $\begin{array}{l}\text { I have stopped socializing with some people because of their reaction to me as a } \\
\text { HCW for people living with COVID-19. }\end{array}$ & $106(42.4)$ & $144(57.6)$ \\
\hline 3. & $\begin{array}{l}\text { I have lost friends because I have told them I provide care to people living with } \\
\text { COVID-19. }\end{array}$ & 179 (71.6) & $71(28.4)$ \\
\hline 4. & $\begin{array}{l}\text { I have been denied social exchanges and friendships because people know that I } \\
\text { care for people living with COVID-19. }\end{array}$ & $140(56)$ & $110(44)$ \\
\hline 5. & $\begin{array}{l}\text { I have felt that people are afraid of me because they think they can get COVID-19 } \\
\text { from me because I care for people living with COVID-19. }\end{array}$ & $93(37.2)$ & $157(62.8)$ \\
\hline 6. & $\begin{array}{l}\text { Some people avoid touching me because they know I take care of COVID-19 } \\
\text { positive patients. }\end{array}$ & $107(42.8)$ & $143(57.2)$ \\
\hline
\end{tabular}

$(\mathrm{p}=0.311$ ) (Table 1). However, the stigma score was significantly high in SRs compared to JRs ( $\left.t=2.207, p=0.029^{*}\right)$ and faculty ( $t=3.825$, $\mathrm{p}=0.001^{* *}$ ). Stigma score was significantly high in JRs compared to faculty $\left(\mathrm{t}=2.493, \mathrm{p}=0.013^{*}\right)$.

Correlation of experienced stigma scale score with age of respondents and hours spent in COVID-19 ward

There was a significant negative correlation $\left(\mathrm{r}=-0.158, \mathrm{p}=0.012^{*}\right)$ between age and experienced stigma score, implying that as the age increased, there was a corresponding reduction in experienced stigma. In addition, there was a significant positive correlation of experienced stigma score with number of hours $\left(\mathrm{r}=0.162, \mathrm{p}=0.010^{*}\right)$ spent in COVID-19 duties. It was also observed that SRs were doing more COVID-19 related duties $(40.13 \pm 15.29 \mathrm{~h} /$ week $)$ than JRs $(28.73 \pm 14.56 \mathrm{~h} /$ week $)$ and faculty $(27.52 \pm 17.92 \mathrm{~h} /$ week $)$.

Responses on individual items of the experienced stigma scale Out of 250 doctors, 187 (74.8\%) agreed or strongly agreed to at least one or more questions (out of six) on the experienced stigma scale, thus they had experienced stigma due to working with patients with COVID-19. Table 2 shows the responses of doctors on individual items of the experienced stigma questionnaire. The response of strongly disagree and disagree were combined in one column as disagreement response. Similarly, the response of strongly agree and agree were combined in one column as agreement response in the next column of Table 2 . Nearly $60 \%$ respondents agreed that they stopped socializing because of people's reactions towards them being a doctor treating COVID-19 $(\mathrm{N}=144)$ and agreed that people avoided touching them because they worked with COVID-19 patients ( $\mathrm{N}=143) .110$ (44\%) respondents agreed to being denied social exchanges/friendships, 88 (35.2\%) agreed being neglected by family or friends and $71(28.4 \%)$ agreed that they lost friendships because they work with patients with COVID-19.

\section{DISCUSSION}

The present study was undertaken to assess actual stigma experienced by doctors, and it was found that $75 \%$ doctors experienced stigma in one or more areas of close relationships. Nearly $60 \%$ doctors had stopped socializing because of people's reactions, they felt that people were afraid of them and that people avoided touching them. These findings show that doctors are increasingly feeling isolated. It is known that experienced stigma can have serious psychological consequences. It can lower self-esteem, quality of life and significantly increase psychological morbidity $[6,24]$. These experiences of stigma are not new for doctors. During SARS outbreak too, $49 \%$ of HCWs had felt stigma of society and 31\% experienced family exclusion [25]. In the time of this COVID-19 pandemic, HCWs are already over-burdened with patient care and experiencing discrimination from others might be precipitating burnout in many of them. Physician burnout can have far-reaching consequences both physically and mentally [26].

HCW: Health care worker 
In our study, 44\% doctors reported that they were denied social exchanges/friendships, $35.2 \%$ were neglected by family/friends and 28.4\% lost friendships because they treated patients with COVID-19. A few previous studies also reported that HCWs experienced rude behavior from other people in their vicinity $[5,18,19]$. It shows that doctors are not only fighting COVID-19, but are also battling stigma.

Resident group of doctors experienced higher stigma in the present study. The resident doctors are younger in age and have comparatively more working hours than faculty group of doctors which could have led to these findings. Younger trainee resident doctors are under maximum pressure for being on the forefront during their duties [9]. The resident group of doctors feel at cross-roads in the time of this pandemic [27]. Their education and training is also getting affected in current times [28]. Sadly, resident doctors not only worked harder in COVID-19 isolation wards, but also bore the brunt of experiencing discrimination from others, as shown by the results of the present study.

There were certain limitations in the study such as, we enrolled only doctors and no other HCWs. We, the authors acknowledge that we specifically wanted to study stigma among doctors since we believed that doctors have been a neglected lot during this crisis. Another limitation could be that, the questionnaire used to measure experienced stigma in the present study was HIV related, which has different modes of transmission compared to COVID-19. However, the authors could not find any questionnaire specific to COVID-19 related stigma at the time of conducting this study. This was the closest as both COVID-19 and HIV are viral infections. Finally, this study reports only cross-sectional data about experienced stigma. This was measured during the first wave of COVID-19 in India. At that time the number of daily confirmed cases of COVID-19 stood at over 62 thousand in India [2]. The findings could have been different during the emergence of second wave [29]. Further research can be undertaken to see the change in stigmatizing attitudes towards doctors with time.

\section{CONCLUSION}

The present study attempted to explore in detail about the experience of stigma among doctors using a brief survey. It showed that considerable stigma was experienced by doctors in the areas of social exchanges, friendships and family relations which might consequently lead to feeling stressed. The findings of present study highlight the need of improving attitudes of community regarding COVID-19 and providing psychosocial support to doctors.

\section{ACKNOWLEDGMENTS}

None.

\section{AUTHORS' CONTRIBUTIONS}

All the authors made substantial contributions towards conducting this research and writing of manuscript.

\section{CONFLICT OF INTERESTS}

None.

\section{AUTHORS FUNDING}

None.

\section{REFERENCES}

1. World Health Organization. WHO Director-general's Opening Remarks at the Media Briefing on COVID-19; 2020. Available from: https:// www.who.int/director-general/speeches/detail/who-director-general-sopening-remarks-at-the-media-briefing-on-covid-19---11-march-2020 [Last accessed on $2021 \mathrm{Feb} 11]$.

2. World Health Organization. WHO Coronavirus Disease (COVID-19) Dashboard; 2021. Available from: https://www.covid19.who.int [Last accessed on 2021 Aug 06].

3. van Brakel WH, Cataldo J, Grover S, Kohrt BA, Nyblade L, Stockton M, et al. Out of the silos: Identifying cross-cutting features of health-related stigma to advance measurement and intervention. BMC Med 2019;17:13.

4. Abdelhafiz AS, Alorabi M. Social stigma: The hidden threat of COVID-19. Front Public Health 2020;8:429.

5. Dye TD, Alcantara L, Siddiqi S, Barbosu M, Sharma S, Panko T, et al. Risk of COVID-19-related bullying, harassment and stigma among healthcare workers: An analytical cross-sectional global study. BMJ Open 2020;10:e046620.

6. van Brakel WH. Measuring health-related stigma-a literature review. Psychol Health Med 2006;11:307-34.

7. Dhanashree, Garg H, Chauhan A, Bhatia M, Sethi G, Chauhan G. Role of mass media and it's impact on general public during coronavirus disease 2019 pandemic in North India: An online assessment. Indian J Med Sci 2021;73:21-5.

8. Menon V, Padhy SK, Pattnaik J. Stigma and aggression against health care workers in India amidst COVID-19 times: Possible drivers and mitigation strategies. Indian J Psychol Med 2020;42:400-4021.

9. Grover S, Rani S, Mehra A, Sahoo S. COVID-19 pandemic: A crisis for health-care workers. J Mental Health Hum Behav 2020;25:1-4.

10. Faris M, Arifianto MR. Social stigma toward health workers associated with coronavirus disease 2019. Open Access Maced J Med Sci 2020;8:112-4.

11. Spoorthy MS, Pratapa SK, Mahant S. Mental health problems faced by healthcare workers due to the COVID-19 pandemic-a review. Asian J Psychiatr 2020;51:102119.

12. Selvaraj P, Muthukanagaraj P, Saluja B, Jeyaraman M, Anudeep TC, Gulati A, et al. Psychological impact of COVID-19 pandemic on health-care professionals in India-a multicentric cross-sectional study. Indian J Med Sci 2020. Doi: 10.25259/IJMS 1932020

13. Gore GA. Doctors and COVID-19: Why we need to be a wise human first! Indian J Med Sci 2020;72:41-3.

14. Pradhan RR, Nepal R. Stigmatization towards healthcare workers during the COVID-19 pandemic in Nepal. Nepalese Med J 2020;3:332-3

15. Uvais NA, Shihabudheen P, Hafi NA. Perceived stress and stigma among doctors working in COVID-19-designated hospitals in India. Prim Care Companion CNS Disord 2020;22:20br02724.

16. Uvais NA, Aziz F, Hafeeq B. COVID-19-related stigma and perceived stress among dialysis staff. J Nephrol 2020;33:1121-2.

17. Teksin G, Uluyol OB, Onur OS, Teksin MG, Ozdemir HM. Stigmarelated factors and their effects on health-care workers during COVID-19 pandemics in Turkey: A multicenter study. Sisli Etfal Hastan Tip Bul 2020;54:281-90.

18. Mostafa A, Sabry W, Mostafa NS. COVID-19-related stigmatization among a sample of Egyptian healthcare workers. PLoS One 2020;15:e0244172.

19. Yadav K, Laskar AR, Rasania SK. A study on stigma and apprehensions related to COVID-19 among healthcare professionals in Delhi. Int J Community Med Public Health 2020;7:4547-53.

20. Garg R, Singla A, Garg J. Perceived stress among doctors working in a dedicated COVID-19 hospital in North India. Indian J Med Sci 2021;73:155-8.

21. Ministry of Health and Family Welfare. Adequate Health Infrastructure and Health Facilities Set Up for COVID-19 Management; 2020. Available from: https://www.pib.gov.in/PressReleasePage. aspx?PRID=1622631 [Last accessed on 2021 Feb 11]

22. Mathur R. National Ethical Guidelines for Biomedical and Health Research Involving Human Participants. New Delhi: Indian Council of Medical Research; 2017.

23. Health Policy Initiative, Task Order 1. Measuring the Degree of HIVrelated Stigma and Discrimination in Health Facilities and Providers: Working Report. Washington, DC: Futures Group, Health Policy Initiative, Task Order $1 ; 2010$.

24. Vani P, Banerjee D. "Feared and avoided": Psychosocial effects of stigma against healthcare workers during COVID19. Indian J Soc Psychiatry 2021;37:14-8

25. Muhidin S, Vizheh M, Moghadam ZB. Anticipating COVID-19related stigma in survivors and health-care workers: Lessons from previous infectious diseases outbreaks-an integrative literature review. Psychiatry Clin Neurosci 2020;74:617-8

26. Menon V, Agrawal V, Joshi S, Ghosh AK. Physician burnout: Quo vadimus? Indian J Med Sci 2020. Doi: 10.25259/IJMS 232020

27. Gundavda KK, Patkar S, Gulia A. Surgical oncology residents' perspective in the COVID-19 pandemic: Standing at crossroads. Indian J Med Sci 2021;73:66-69.

28. Giliyaru S, Hegde G, Gajjala S, Vemuri O, Azzopardi C, Hurley P, et al. COVID-19 pandemic and medical education. Indian J Med Sci 2021;73:64-5

29. Parikh P, Joshi S, Gulia A. Resurgence of COVID-19 in Indiachallenges and solution. Indian J Med Sci 2021;73:70-4. 